\title{
Effect of Muscle Relaxation on Hemodialysis Patients' Pain
}

\author{
Baloochi Beydokhti T.1 MSc, Kianmehr M.2 PhD, Tavakolizadeh J. ${ }^{3}$ PhD, \\ Basiri-Moghadam M. ${ }^{1}$ MSc, Biabani F.* BSc
}

\author{
*Nursing Department, Nursing \& Midwifery Faculty, Gonabad University of Medical Sciences, Gonabad, Iran \\ 1 Social Development \& Health Promotion Research Center, Gonabad University of Medical Sciences, Gonabad, \\ Iran \\ 2Medical Physics Department, Medicine Faculty, Gonabad University of Medical Sciences, Gonabad, Iran \\ ${ }^{3}$ Basic Sciences Department, Medicine Faculty, Gonabad University of Medical Sciences, Gonabad, Iran
}

\begin{abstract} the effect of muscle relaxation on hemodialysis patients' pain. square, independent T and Mann-Whitney tests by SPSS 21 software. control $(\mathrm{p}=0.03)$. in hemodialysis patients.

\section{Keywords}

Muscle Relaxation [http://www.ncbi.nlm.nih.gov/mesh/68009126];

Pain [http://www.ncbi.nlm.nih.gov/mesh/68010146];

Renal Dialysis [http://www.ncbi.nlm.nih.gov/mesh/68006435]
\end{abstract}

Aims: Dialysis patients have experienced some degree of pain, especially foot pain. Some complementary interventions such as muscle relaxation are effective in relieving pain. This study was performed with the aim of assessing

Materials \& Methods: This randomized controlled clinical trial was conducted on 90 hemodialysis patients of Khatamolanbia and Imam Ali hemodialysis centers of Zahedan during 2013 and 2014. The patients were chosen by purposive sampling based on inclusion criteria and randomly divided into control and experimental groups. Pain intensity was measured by McGill questionnaire before intervention. Then, Benson muscle relaxation was taught to patients' of case group and was performed by them for 15-20 minutes twice a day for a month. The control group received no training. The pain intensity of two groups was compared after one month. The data were analyzed using Chi-

Findings: Most of the patients were men, married, housekeeper with under diploma education and the mean age of them was $43.0 \pm 15.0$ years. There was a significant decrease in pain intensity in the intervention group compared to the

Conclusion: The muscle relaxation technique can be employed to reduce pain

\author{
* Corresponding Author \\ Tel: +985632624300 \\ Fax: +985632621912 \\ Address: Shahid Atashdast Hospital, Emam Khomeyni Boulevard, Nehbandan. Iran \\ biabanif@gmu.ac.ir \\ Received: January 13, $2015 \quad$ Accepted: May 5, 2015 ePublished: June 20, 2015
}


مقدمه

مرحله انتهايى بيمارى كليوى (ESRD)، اختلال عملكرد ييشرونده كليه است كه شيوع آن رو به افزايش است [1]. يكى از

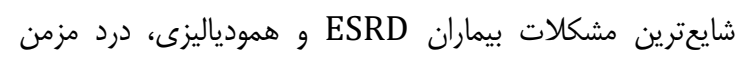

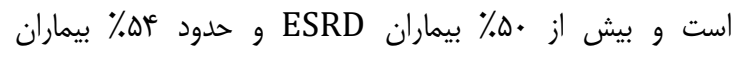

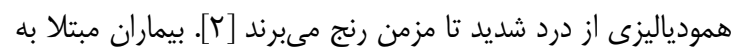

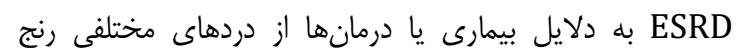

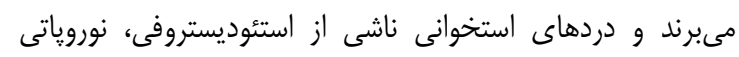

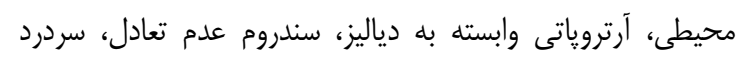

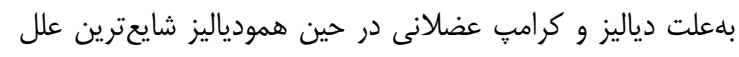

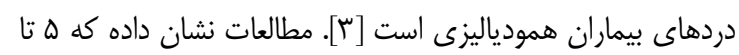

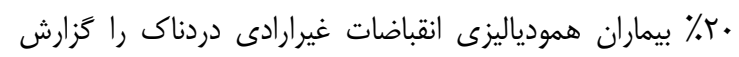

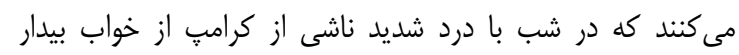

مىشوند و در روز باعث اختلال در فعاليتهاى آنها مى شود [ع].

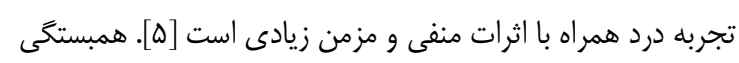

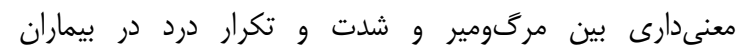

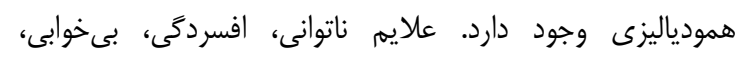

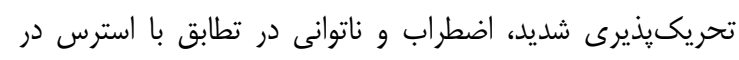

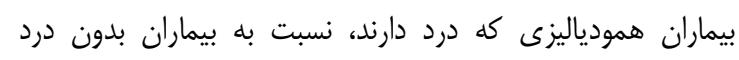

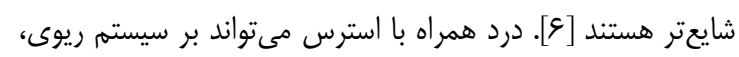

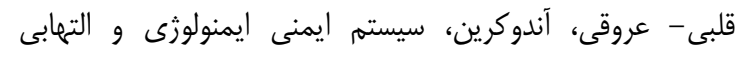

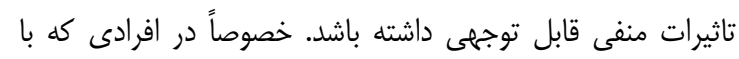

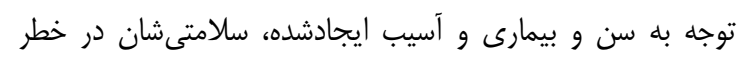

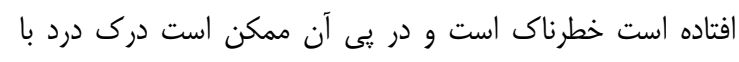

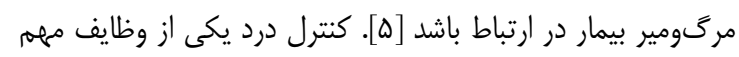
يرستارى است. روشهاى تسكين درد به دو صورت دارويى و

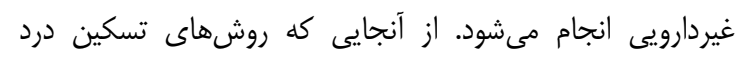
دارويى داراى عوارض جانبى زيادى هستند و تصميمثيرى و ودئ

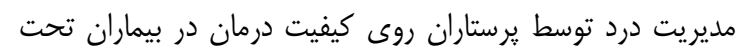

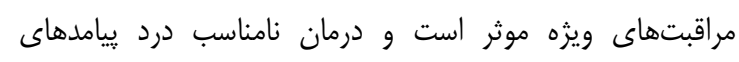

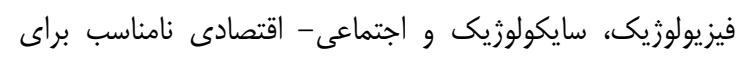

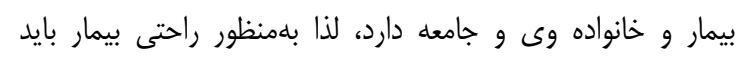

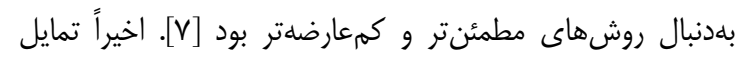

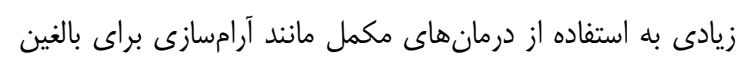

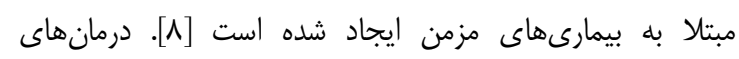

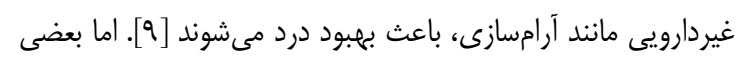

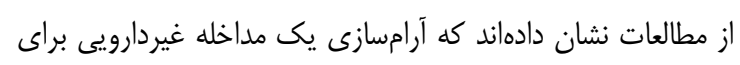
درمان درد در موقعيتهاى متفاوت يزشكى است و مطالعات معمولاً از تركيب آرامسازى، ماساز یشت يا مجسمسازى استفاده نمودهاند

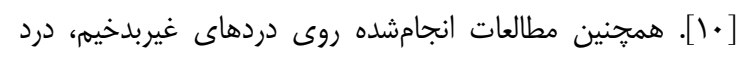

$$
\text { كردنى طولانى مدت و آرترويلاستى زانو بوده است [11]. }
$$

تاثير تكنيك آرامسازى عضلانى بردئ درد برد بيماران

\section{همودياليزى}

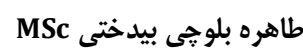

مركز تحقيقات توسعه اجتماعى و ارتقاى سلامت، دانشخاه علوم يزشكى گَناباد، كناباد، ايران

PhD مجتبى كيان مهرب

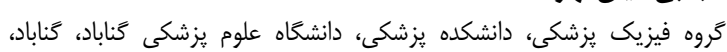

ايران

جهانشير توكلىزاده PhD

كروه علوم پايه، دانشكده يزشكى، دانشخاه علوم يزشكى گناباد، گناباد، ايران

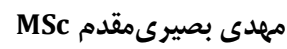

مركز تحقيقات توسعه اجتماعى و ارتقاى سلامت، دانشخاه علوم يزشكى گَناباد، كناباد، ايران

BSc "فاطمه بيابانى

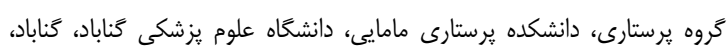

ايران

جكيده

اهداف: بيماران دياليزى درجاتى از درد خصوصاً درد يا را تجربه مى كنند.

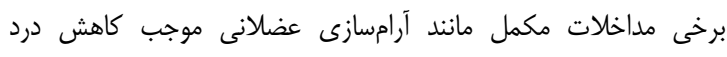

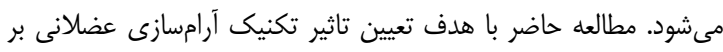

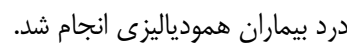

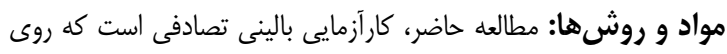

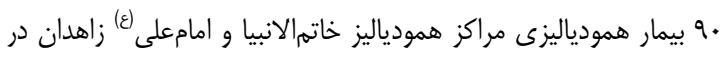

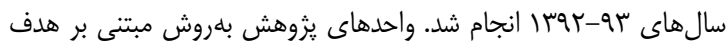

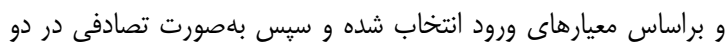

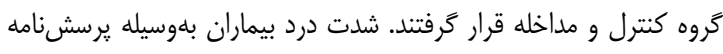

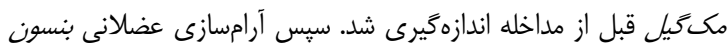

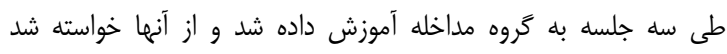

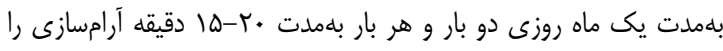

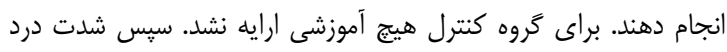

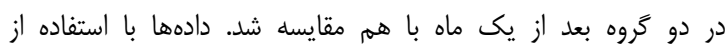

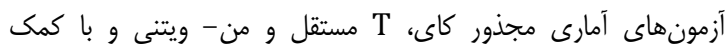

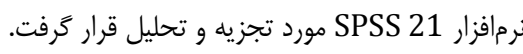

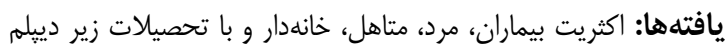

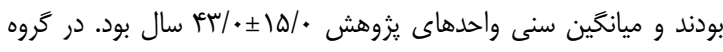

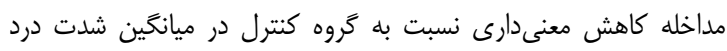

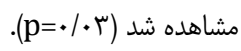
نتيجهَيرى: مىتوان از تكنيك آرامسازى عضلانى (برانى براى كاهش درد بيماران همودياليزى استفاده كرد. كليدوازهها: آرامسازى عضلانى، درد، همودياليز

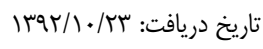

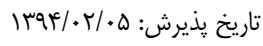

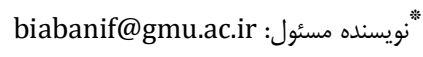

دوره آr، شماره r، تابستان Iraf

فصلنامه افق دانش 
Vاثير تكنيك آرامسازى عضلانى بر درد بيماران همودياليزى

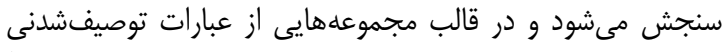
بيان مىشود. كلماتى كه در زير يك مجموعه قرار دارند، معمولاً بيشترين تشابه را با هم دارند. بدون شك، بعضى از اين كلمات

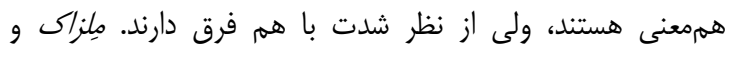

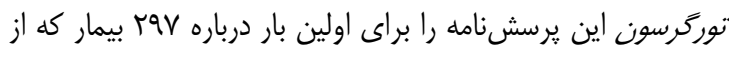

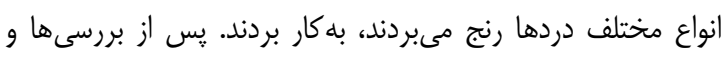

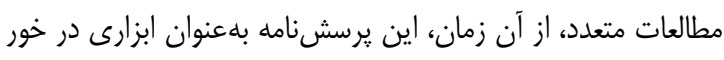
اعتماد، براى مطالعه و بررسى درد با روشهاى مختلف بالينى إنى

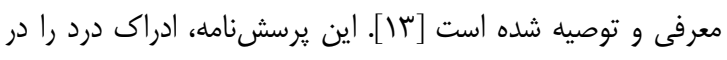

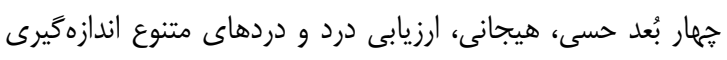

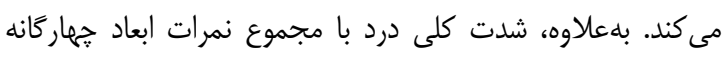

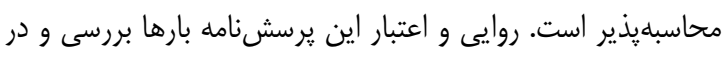

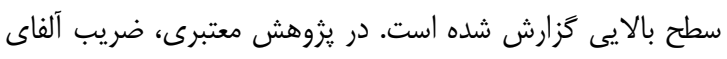

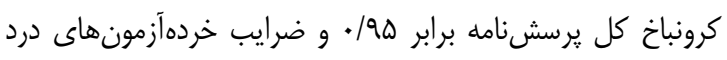

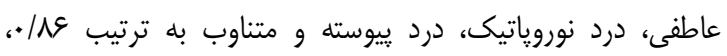

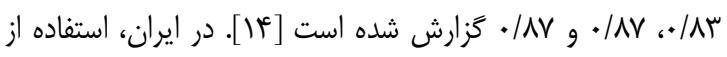
اين يرسشنامه در بررسىهاى بالينى به جامعه ايرانى توصيه شده است [مهاين روش كار به اين صورت بود كه ابتدا از بيماران خواسته شد تا

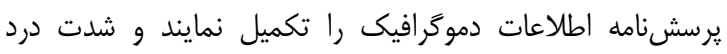
بيماران نيز تعيين شد. سيس تكنيك آرامسازى عضلانى بلهصورات

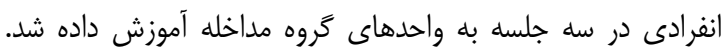

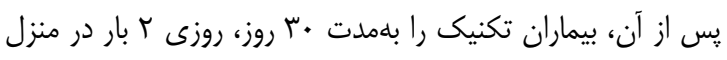

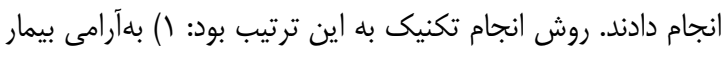

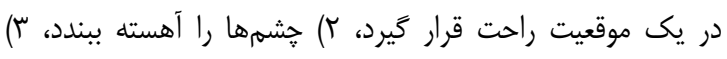

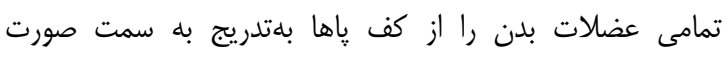

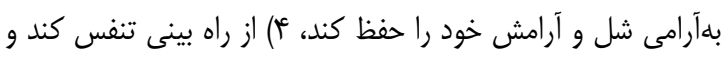

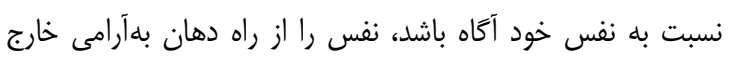

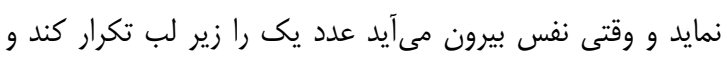

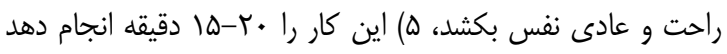

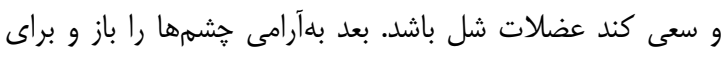
جند دقيقه از جا بلند نشود و \&) نخران نباشد به سطح عميقى از باز

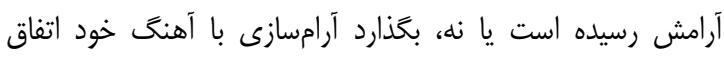

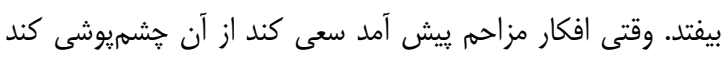

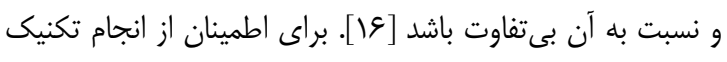

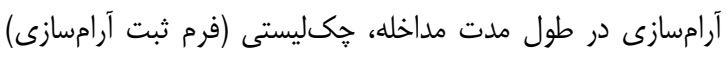
در اختيار نمونهها قرار گرفت تا روز، ساعت، طول مدت مدات آرامسازى و

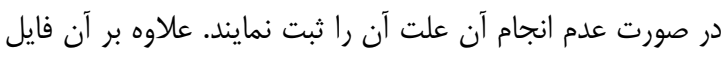

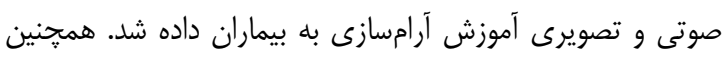

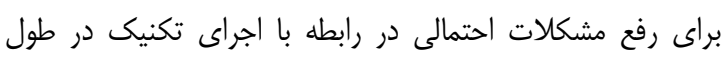

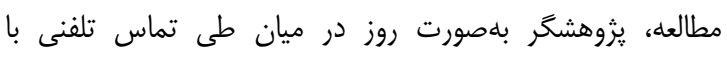
واحدهاى يثوهش، روند اجراى تكنيك و تكميلنمودن فرم ثبت بروني

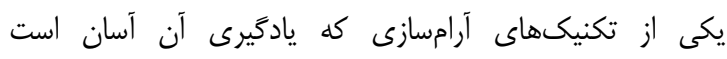

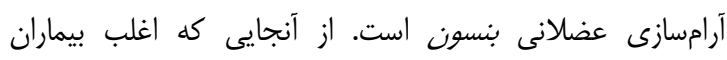

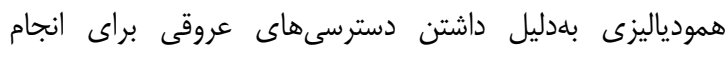

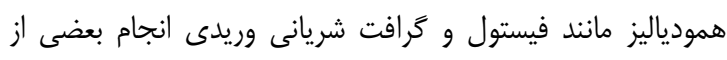

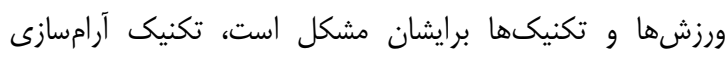

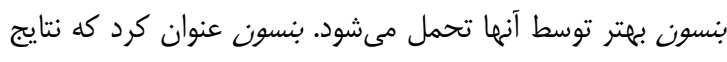

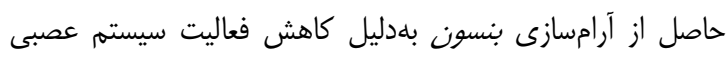

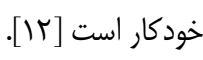
لذا اين مطالعه با هدف تعيين تاثير تكنيك آرامسازى عضلانى بنسون بر درد بيماران همودياليزى انجام شد.

\section{مواد و روشها}

اين مطالعه كارآزمايى بالينى تصادفى شاهددار در كليه بيماران تحت

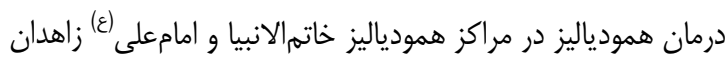

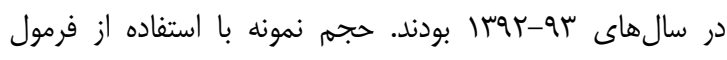

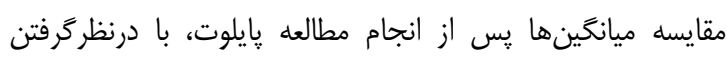

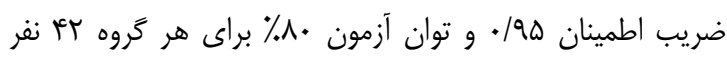

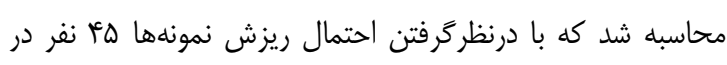

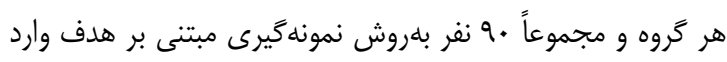

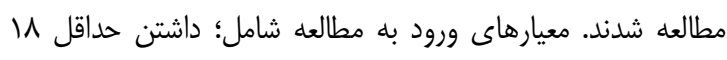

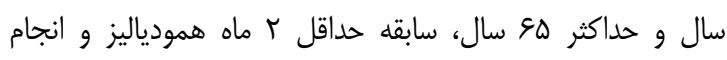

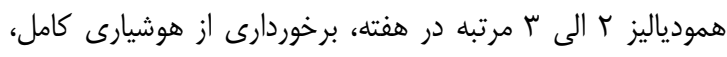

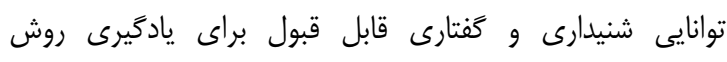

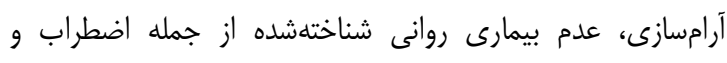

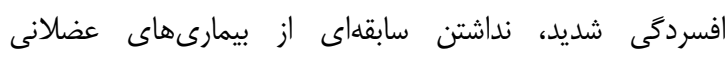

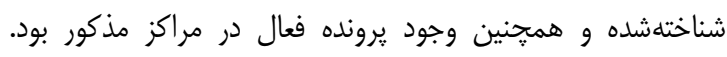

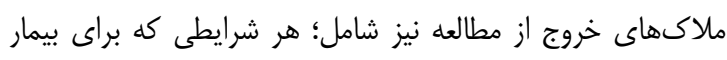

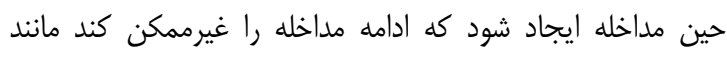

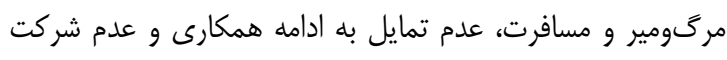

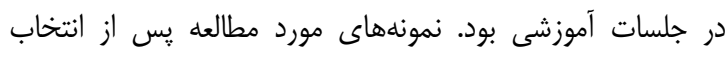

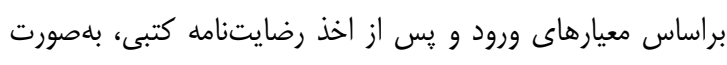

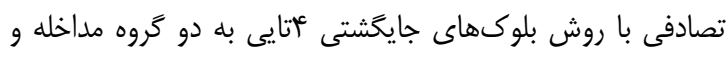
كتنرل تخصيص يافتند.

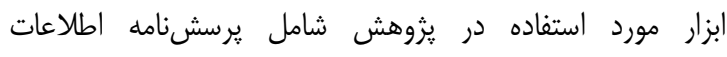

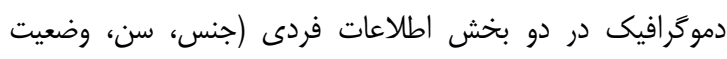

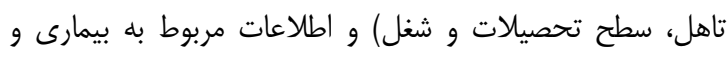

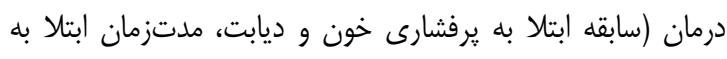

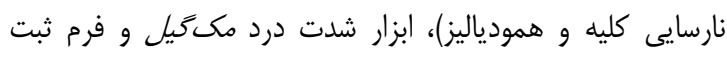

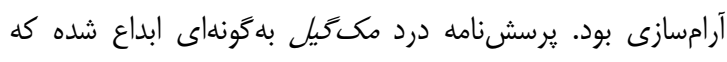

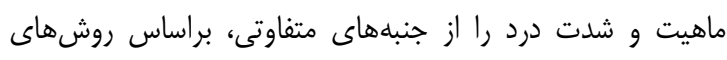

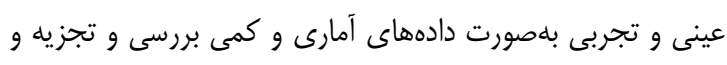

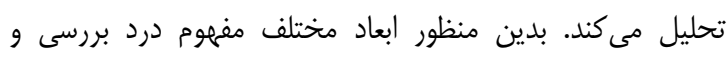


يثوهش در دو گروه، مرد، متاهل، بىسواد و خانهدار بودند. دو گروه

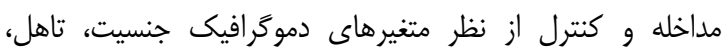
تحصيلات و شغل تفاوت معنىدارى نداشتند و همكَن بودند. همجنين در رابطه با اطلاعات مربوط به بيمارى، اكثريت واحدها داراى سابقه افزايش فشار خون بودند، ولى سابقه ديابت نداشتند.

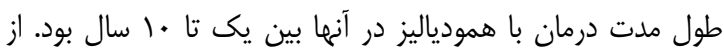

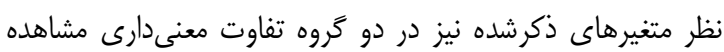

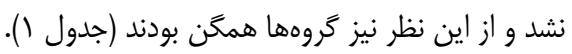

\begin{tabular}{|c|c|c|}
\hline سبل و بعد از مداخله & كَر مروه مداخله & كرووه كنترل معايسه \\
\hline \multirow{3}{*}{ 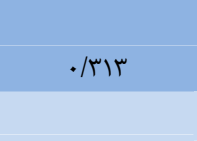 } & & 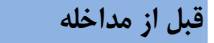 \\
\hline & $|r / 8| \pm \mid q / 9 r$ & $\Lambda / 4 \cdot \pm I V / V \Lambda$ \\
\hline & & بعد از مداخله \\
\hline \multirow[t]{2}{*}{. } & $1 . / R+1 \varepsilon / \Delta F$ & $|r / g r \pm r| / V \Lambda$ \\
\hline & \multicolumn{2}{|c|}{ اختلاف ميانكين قبل و بعد از مداخله } \\
\hline 年 & $-r / r \Lambda \pm r / \Lambda q$ & $+L / 4 t \pm I T / 4 t$ \\
\hline
\end{tabular}

قبل از مداخله، ميانخين نمره شدت درد در گروه مداخله بالاتر از

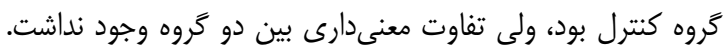

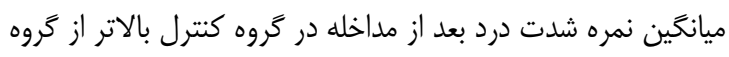

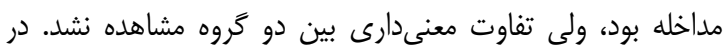

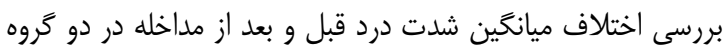

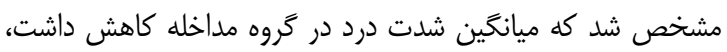

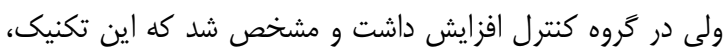
كاهش معنىدارى در شدت درد ايجاد نمود (جدول ؟ ؟).

\section{بحث}

در يروهش حاضر تاثير تكنيك آرامسازى عضلانى بنسون بر شدت درد بيماران تحت همودياليز بررسى شد. طبق نتايج اين مطالعه، تئين

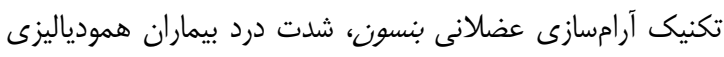

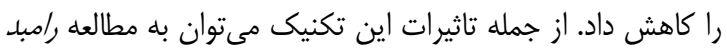

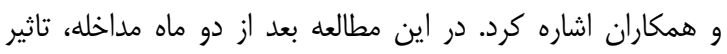

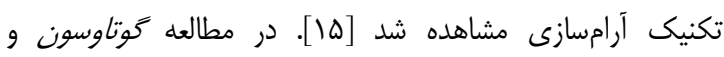

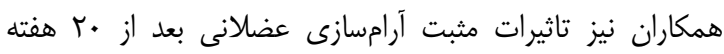

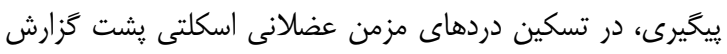
شد [IV]، ولى در مطالعه حاضر با مداخله يك ئى ماه نتايج معنى دار كزارش شده است. بهمنظور بررسى تاثير تكنيك آرامسازى بر شدات درد مطالعاتى انجام شده است؛ از جمله در مطالعات هيه و همكاران تهان

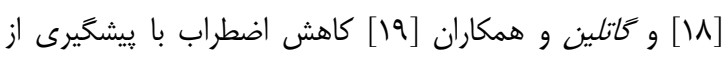

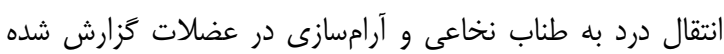

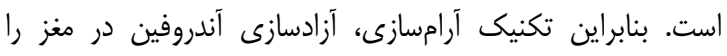

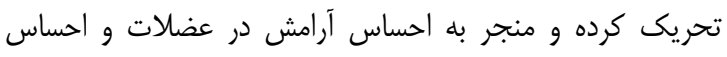

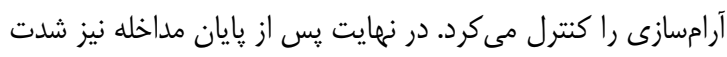

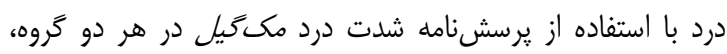

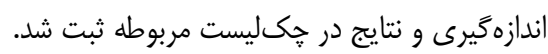

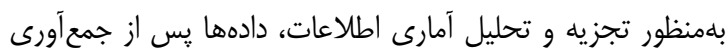

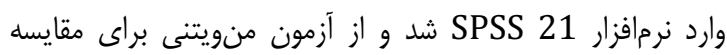

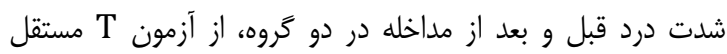

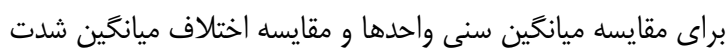

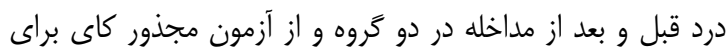
مقايسه متغيرهاى كيفى يثوهش در دو زروه، در سطح معنى دارى كوجى جتر از هـ • • استفاده شد.

جدول () مقايسه توزيع فراوانى (اعداد داخل برانتز درصد هستند) ويزگكىهاى

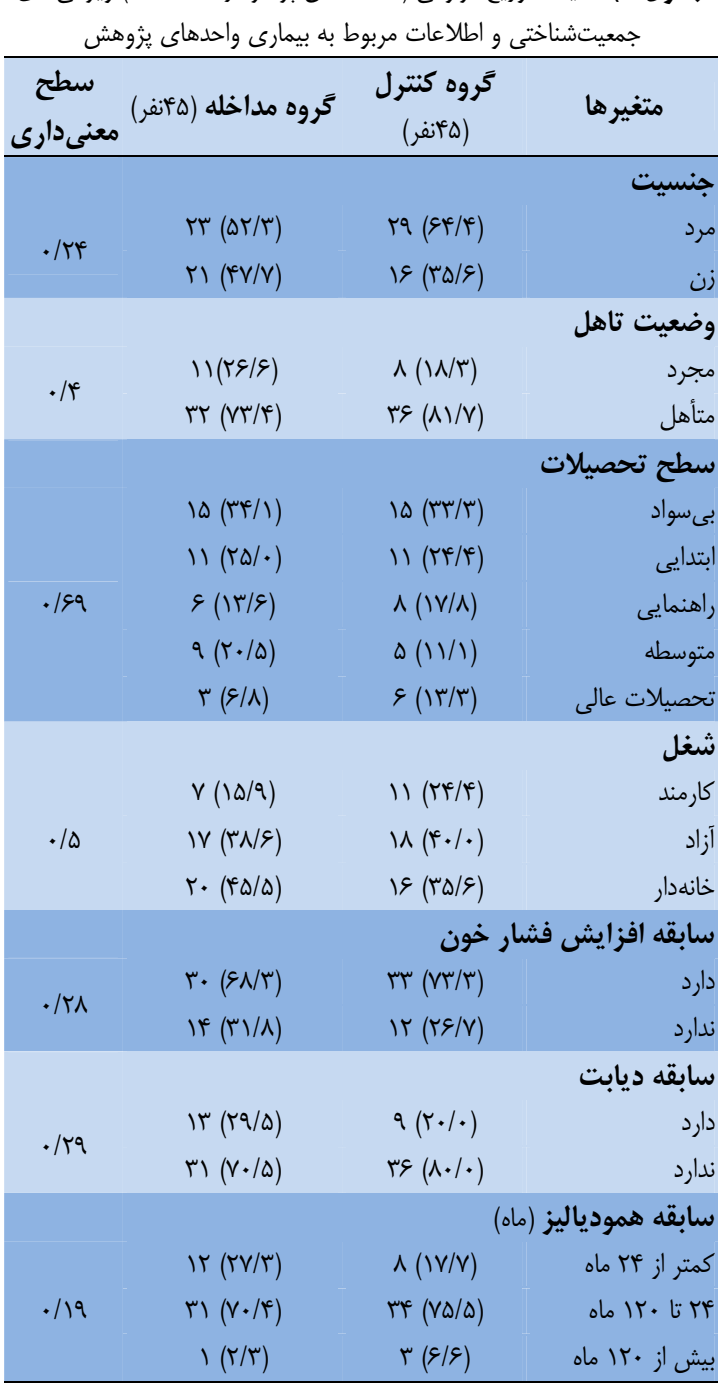

يافتهها

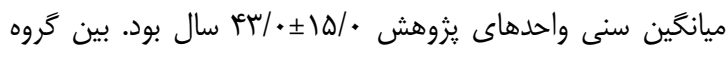

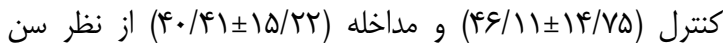

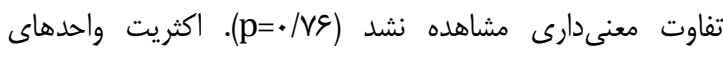

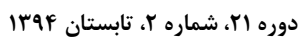
فصلنامه افق دانش 
V9 اثير تكنيك آرامسازى عضلانى بر درد بيماران همودياليزى

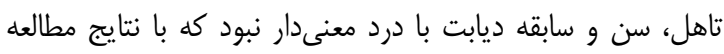

هليك و همكاران مطابقت دارد [•r].

يكى از مهمترين محدوديتهاى اين يزوهش تكميل يرسشنامه تهري

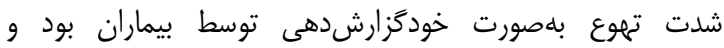
محدوديت ديخر آن عدم دسترسى مستقيم به بيمار و نظارت مستمر

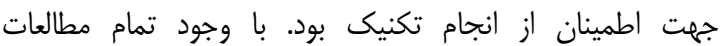
انجامشده در زمينه تاثير آرامسازى و نتايج حاصل از آنها كه اكثريت با نتايج مطالعه حاضر مطابقت دارد، انجام مطالعات تكميلى در اين زمينه و مقايسه ساير روشهاى غيردارويى با روش مورد استفاده در

$$
\text { اين مطالعه يِيشنهاد مى شود. }
$$

\section{نتيجل كَيرى}

با تمرينات ساده آرامسازى عضلانى بنسون بدون هزينه، بهآسانى و

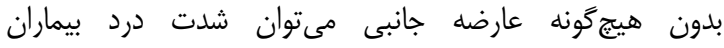
همودياليزى را بهبود بخشيد.

تثشكر و قدردانى: بدين وسيله از شوراى تحصيلات تكميلى و

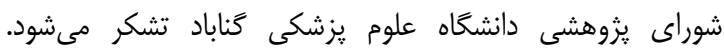

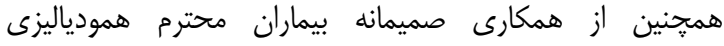

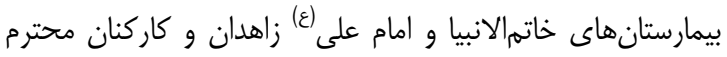
اين بيمارستانها بهخصوص خانمها نيكيور، خاقانى، نيكسبخت،

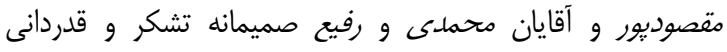
مى شود.

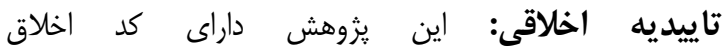

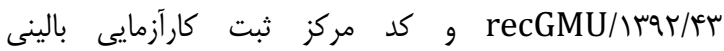
IRCT2014051117656N1 تعارض منافع: هيج گَنه تعارض منافع توسط نويسندكان بيان

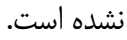
منابع مالى: اين مقاله حاصل يايان نامه دانشجويى بلهنظور اخذ درجه كارشناسىارشد يرستارى مراقبتهاى ويثه است.

\section{منابع}

1- Baraz S, Parvardeh S, Mohammadi E, Broumand B. Dietary and fluid compliance: An educational intervention for patients having haemodialysis. J Adv Nurs. 2010;66(1):60-8.

2- Masajtis Zagajewska A, Pietrasik P, Krawczyk J, Krakowska M, Jarzebski T, Pietrasiewicz B, et al. Similar prevalence but different characteristics of pain in kidney transplant recipients and chronic hemodialysis patients. Clin Transpl. 2011;25(2):144-51.

3- Shayamsunder AK, Patel SS, Jain V, Peterson RA, Kimmel PL. Sleepiness, and pain in end-stage renal disease: Distressing symptoms for patients. Semin Dial. 2005;18(2):109-18.

4- Khajehdehi P , Mojerlou M, Behzadi S, Rais Jalali GA. A randomized, double-blind, placebo controlled
شادى در فرد مىشود. همجنين سطوحى از بىدردى را براى مدت

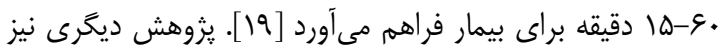
توسط جنسن و همكاران انجام و آرامسازى بلهروش جاكوبسون

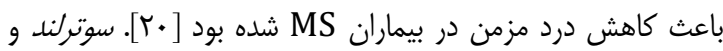

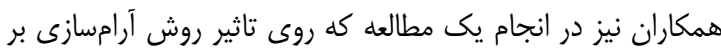

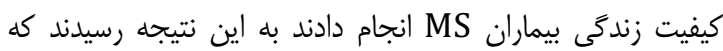
روش آرامسازى با تسكين درد بيماران مزمن موجب كسب انرزى دئى بيشتر و محدوديت حركتى كمتر بيماران مىشود. اين در حالى بود

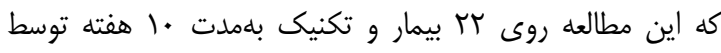
واحدهاى يزوهش انجام شد [ [r]. همجنين فر/هانى و همكاران در مطالعهاى كه در مورد شدت درد درد و خارش و علايم حياتى بيماران مبتلا به سوختخى انجام دادند، نتايج

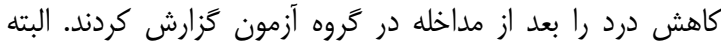

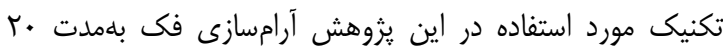
دقيقه بود كه نتايج حاصل با يافتههاى اين يثوهش همسو است.

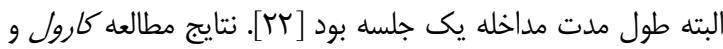

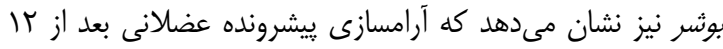

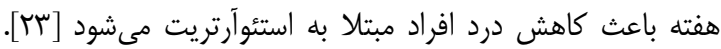
نتايج مطالعه/مرى و همكاران نشان مىدهد كه آرامسازى ييشرونده

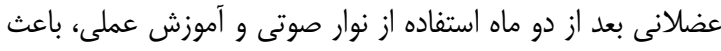

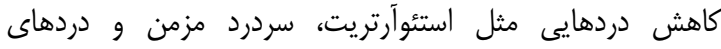
سرطانى مىشود [4r]. مطالعه بودزينسكى و همكاران نشان مى دهد كه آرامسازى ييشرونده عضلانى بعد از عا جلسه آموزش و دو ماه ماه انجام آرامسازى توسط بيماران بر كاهش دردهاى عصبى تاثير

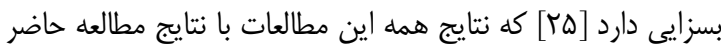
مطابقت دارد. اگرجه در بيشتر مطالعات ذكرشده مدت مداخله دو يا سه ماه بوده است، ولى در مطالعه حاضر با وجود كوتاهتر بودن زمان مداخله، نتايج آمارى معنىدارى بلهدست آمد. در همين رابطه مطالعه

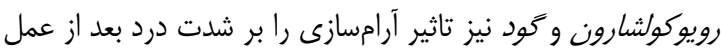

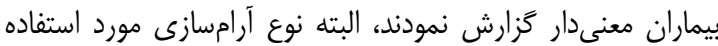

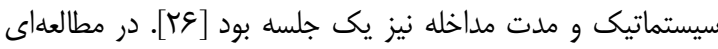

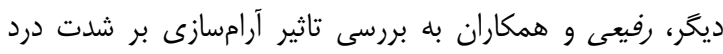

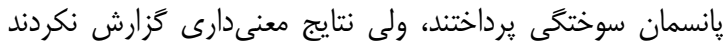

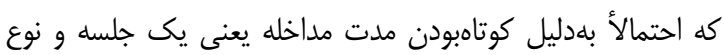

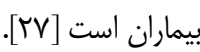
آرامسازى داراى اثرات مثبت زيادى مانند كاهش ضعف و خستخى، افزايش تاثير داروهاى ضددرد، انحراف فكر بيمار از درد، افزايش ميزان تحمل بيمار و مشاركت بيشتر بيمار در درمان درد است [براتئ.

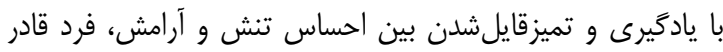

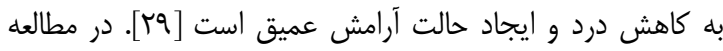
حاضر، ارتباط برخى عوامل از قبيل شغل، تحصيلات، جنسيت، 
18- Heye ML, Foster L, Bartlett MK, Adkins S. A preoperative intervention for pain reduction, improved mobility, and self-efficacy. Appl Nurs Res. 2002;15(3):174-83.

19- Gatlin CG, Schulmeister L. When medication is not enough: Nonpharmacologic management of pain. Clin J Oncol Nurs. 2007;11(5):699-704.

20- Jensen MP, Barber J, Romano JM, Molton IR, Raichle KA, Osborne TL, et al. A comparison of Self-hypnosis versus Progressive muscle relaxation in patients with multiple sclerosis and chronic pain. Int J Clin Exp Hypn. 2009;57(2):198-21.

21- Sutherland G, Andersen MB, Morris T. Relaxation and health-related quality of life in multiple sclerosis: The example of autogenic training. J Behav Med. 2005;28(3):249-56.

22- Varvani Farahani P, Hekmatpou D, Shamsi Khani S. Effectiveness of muscle relaxation on pain, pruritus and vital signs of patients with burns. Iran J Crit Care Nurs. 2013;6(2):87-94.

23- Bikmoradi A, Zafari A, Oshvandi Kh, Mazdeh M, Roshanaei Gh. Effect of progressive muscle relaxation on severityof pain in patients with multiple sclerosis: A randomized controlled trial. Hayat. 2014;20(1):26-37. [Persian]

24- Emery CF, France CR, Harris J, Norman G, Vanarsdalen C. Effect of progressive muscle relaxation training on nociceptive flexion reflex threshold in healthy young adults: A randomized trial. Pain. 2008;138(2):375-9.

25- Budzynski T, Stoyva J, Adler C. Feedback induced muscle relaxation: Application to tension headache. J Behav Ther Exp Psychiat. 1970;1(3):205-11.

26- Roykulcharoen V, Good M. Systematic relaxation to relieve postoperative pain. J Adv Nurs. 2004;48(2):1408.

27- Rafiei F, Mohammadi Fakhar F, Jamshidi Ourak R, Inanlou M. Effect of Jaw relaxation on pain intensity of burn dressing. Iran J Crit Care Nurs. 2010;3(2):51-3.

28- Elizabet B. Muscle therapy in pain and symptom management. J Palliat Care. 2003;9(4):491-6.

29- Shaban M, Rasoolzadeh N, Mehran A, Moradalizadeh F. Study of two non-pharmacological methods, progressive muscle relaxation and music, on pain relief of cancerous patients. Hayat. 2006;12(3):63-72. [Persian]

30. Celik O, Ozbek O, Yilmaz M, Duman I, Ozbek S. Apiliogullari S. Vapocoolant spray vs Lidocaine cream for reducing the pain of venipuncture in hemodialysis patients: A randomized placebo, controlled, crossover study. Int J Med Sci. 2011;8(7):623-7.
Trial of supplementary vitamins E, C and their combination for treatment of haemo dialysis cramps. Nephrol Dial Transplant. 2001;16(7):1448-51.

5- Alhani F. The effect of programmed distraction on the pain caused by venipuncture among adolescents on hemodialysis. Pain Manag Nurs. 2010;11(2):85-91.

6- Downie WW, Leatham PA, Rhind VM, Wright V, Branco JA, Anderson JA. Studies with pain rating scales. Ann Rheum Dis. 1978;37(4):378-81.

7- Ghods AA, Abforosh N, Ghorbani R, Asgari MR. Effect lavender Inhalation on pain intensity during insertion of vascular needles in hemodialysis patients. JBUMS. 2014;16(10):7-14. [Persian]

8- Tsai SL. Audio-visual relaxation training for anxiety, sleep, and relaxation among Chinese adults with cardiac disease. Res Nurs Health. 2004;27(6):458-68.

9- Kwekkeboom KL, Cherwin CH, Lee JW, Wanta B. Mindbody treatments for the pain-fatigue-sleep disturbance symptom cluster in persons with cancer. J Pain Symptom Manage. 2010;39(1):126-38.

10- Chen YL, Francis AJ. Relaxation and imagery for chronic, nonmalignant pain: Effects on pain symptoms, quality of life, and mental health. Pain Manag Nurs. 2010;11(3):159-68.

11- Buyukyılmaz F, Asti T. The effect of relaxation techniques and back massage on pain and anxiety in Turkish total hip or knee arthroplasty patients. Pain Manag Nurs. 2013;14(3):143-54.

12- Mohammadi Fakhar F, Rafii F, Jamshidi Orak R. The effect of jaw relaxation on pain anxiety during burn dressings: Randomised clinical trial. Burns. 2013;39(1):61-7.

13- Melzack R, Torgerson WS. On the language of pain. Anesthesiol. 1971;34(1):50-9.

14- Dworkin RH1, Turk DC, Revicki DA, Harding G, Coyne KS, Peirce-Sandner S, et al. Development and initial validation of an expanded and revised version of the Short-form McGill Pain Questionnaire (SF-MPQ-2). Pain. 2009;144(1-2):35-42.

15- Rambod M, Sharifi F, Pourali Mohammadi N, Pasyar $\mathrm{N}$, Rafii F. Evaluation of the effect of Benson's relaxation technique on pain and quality of life of haemo dialysis patients: a randomized controlled trial. Int J Nurs Stud. 2014;51(7):964-73.

16- Elali ES, Mahdavi A, Jannati Y, Yazdani J, Setareh J. Effect of Benson relaxation response on stress among in hemodialysis patients. J Mazandaran Univ Med Sci. 2012;22(91):61-8. [Persian]

17- Linton SJ. Chronic back pain: Integrating psychological and physical therapy: An overview. Behav Med. 1994;20(3):101-4. 